\title{
EXPRESSÃO TRANSIENTE DO GENE gus, SOB REGULAÇÃO DE QUATRO PROMOTORES, EM DIFERENTES TECIDOS DE MAMOEIRO (Carica papaya L.) E VIDEIRA (Vitis sp.) ${ }^{1}$
}

\author{
ADELAR ALMEIDA PINTO², MARLY CATARINA FELIPE COELHO ${ }^{3}$, MANOEL TEIXEIRA SOUZA JR., \\ MIGUEL PEDRO GUERRA ${ }^{2}$
}

\begin{abstract}
RESUMO - O mamoeiro (Carica papaya L.) e a videira (Vitis vinifera L.) destacam-se entre as fruteiras produzidas no Brasil por serem plantadas em quase todo o território nacional e apresentarem importância econômica e social. A tecnologia de produção de organismos geneticamente modificados, também conhecidos como "transgênicos", tem grande potencial de uso no desenvolvimento de fruteiras melhoradas. Porém, questões de propriedade intelectual limitam o uso da engenharia genética por países em desenvolvimento, que normalmente não detêm direitos sobre processos ou produtos necessários ao uso desta. Neste contexto, o presente estudo buscou avaliar promotores de expressão gênica alternativos ao CaMV 35S, que é o mais utilizado no desenvolvimento de transgênicos, mas é patenteado. Para tanto, construções gênicas com o gene gus sob a regulação de diferentes promotores foram testadas para expressão transiente em diversos tecidos de mamoeiro e videira. Expressão transiente foi avaliada em embriões somáticos, folhas, caules, raízes e frutos. O promotor do gene $U B Q 3$, que é constitutivo e se encontra em domínio publico, mostrou ser uma alternativa promissora para futuros trabalhos de transformação genética de mamoeiro, mas não de videira.
\end{abstract}

Termos para indexação: $\beta$-glucuronidase, expressão transiente e promotores.

\section{TRANSIENT EXPRESSION OF THE gus GENE, UNDER THE REGULATION OF FOUR PROMOTERS, ON DIFFERENT TISSUES OF PAPAYA (Carica papaya L.) AND GRAPE (Vitis sp.)}

\begin{abstract}
Papaya (Carica papaya L.) and grapes (Vitis vinifera L.) are among the most important fruit crops produced in Brazil, and are cultivated in several regions around the country being of economical and social importance. Genetic engineering has great potential on the development of genetically improved fruit crops. However, intellectual property issues constantly limit the commercial use of this technology in developing countries. Thus, the present study aimed to evaluate gene promoters as alternatives to the $35 \mathrm{~S} \mathrm{CaMV}$, which is the most used so far in the development of transgenic plants, but it is patented. In order to do that, the expression of the gus gene under the regulation of distinct promoters was evaluated on different papaya and grape tissues. Transient expression was evaluated on somatic embryos, leaves, stems, roots and fruits. The $U B Q 3$ promoter, which is constitutive and is in the public domain, showed to be a real promising alternative for future work on genetic transformation of papaya but not grapes.
\end{abstract}

Index terms: $\beta$-glucuronidase, transient expression and promoters.

O mamoeiro (Carica papaya L.) e a videira (Vitis vinifera L.) são cultivados em quase todo o território nacional, apresentando importância tanto econômica como social. O mamoeiro tem sua produção bastante limitada por vários patógenos, cabendo destacar os de origem viral. A "mancha anelar do mamoeiro" é o principal problema fitossanitário desta cultura no mundo, sendo causada por um vírus, o Papaya ringspot virus (PRSV). Diversas estratégias já foram aplicadas visando ao controle desta doença (Isherwood, 1992; Rezende \& Costa, 1993; Yeh \& Gonsalves, 1994), porém nenhuma possibilita um controle amplo e duradouro. Nesse sentido, o desenvolvimento de mamoeiros transgênicos resistentes a vírus tem uma grande importância. Mamoeiros transgênicos resistentes ao PRSV, expressando o gene da capa protéica deste vírus, já foram obtidos (Fitch et al., 1992; Cai et al.,1999; Souza Jr., 1999), e duas variedades já se encontram no mercado (Gonsalves, 1998). O domínio da tecnologia de transformação genética de mamoeiro abre a possibilidade de adicionar novos valores agregados a esta cultura, tais como resistência a fungos, vida de prateleira mais longa, etc. No caso da videira, as doenças fúngicas são responsáveis por perdas substanciais em produtividade e qualidade do fruto. $\mathrm{O}$ uso de cultivares resistentes obtidas por melhoramento genético convencional tem sido uma das principais formas de controle de pragas nesta cultura. Porém, devido ao seu longo ciclo vegetativo (2-3 anos), esses programas de melhoramento necessitam de um longo período para o desenvolvimento de novas variedades (Camargo et al., 1999). Nesse sentido, a engenharia genética apresentase como uma ferramenta promissora para o desenvolvimento de cultivares resistentes. Vários sistemas-modelo para transformação de videira já foram estabelecidos (Kikkert et al., 1997), podendo ser aplicados para o melhoramento de variedades comercialmente importantes.

Um dos principais fatores que limitam o desenvolvimento de plantas transgênicas em países subdesenvolvidos e em desenvolvimento, é a dependência do uso de produtos ou processos biotecnológicos que se encontram sob proteção intelectual ou patentes. Dentre estes, cabe destacar os promotores de expressão, que são regiões regulatórias de genes necessárias à transcrição dos mesmos. Um dos promotores mais utilizados em biotecnologia de plantas é o $35 \mathrm{~S}$ do Cauliflower mosaic virus (CaMV) (Benfey \& Chua, 1990), que confere uma alta taxa de expressão na maioria das células quando transferido para plantas. Porém, este promotor é patenteado, o que demanda, quando do seu uso em plantas transgênicas que visam ao mercado, negociação para obtenção de licenciamento para uso comercial.

O presente estudo objetivou comparar a expressão transiente da b-glucuronidase (gus) sob regulação de três promotores de expressão gênica, em diversos tecidos de mamoeiro e videira, tendo o promotor CaMV 35S como base comparativa. O gene gus, isolado de Escherichia coli (Jefferson et al., 1986), é um gene repórter bastante utilizado no estudo e monitoramento da expressão gênica, principalmente no que diz respeito à especificidade de seqüências de promotores (Gilissen et al., 1998).

Frutos, folhas, caules e raízes foram obtidos de mamoeiros 'Sunrise' coletados no campo. Análises nos frutos, caule e raízes foram efetuadas tanto no tecido da superfície quanto no tecido interno destes órgãos. Além destes tecidos, foram utilizados embriões somáticos estabelecidos in vitro segundo Souza Jr. (1999). Foram utilizadas folhas e caules de plantas de videira da variedade copa 'Cabernet Sauvignon', e folhas, caules e raízes, do porta-enxerto 'Paulsen-1103', além de culturas de calos, previamente estabelecidas segundo Martinelli et al. (1994), provenientes de cultura de tecidos de ovários.

As construções gênicas utilizadas foram: o plasmídeo pBI426 (Datla et al., 1991), que contém o gene gus sob o controle do promotor CaMV 35S duplo (35S-35S) (Benfey \& Chua, 1990); o plasmídeo pAG1

1 (Trabalho 120/2001). Recebido: 14/06/2001. Aceito para publicação: 21/08/2002.

2 Departamento de Fitotecnia, UFSC, Centro de Ciências Agrárias, CP 476, Florianópolis - SC, CEP 88034-001

3 Embrapa Recursos Genéticos e Biotecnologia, CP 0237, Brasília - DF, CEP 70770-900. e-mail: msouza@ cenargen.embrapa.br 
(Aragão et al., 2000), que contém o gene gus sob o controle do promotor do gene act2 de A. thaliana (Yong-Qiang et al.,1996); o plasmídeo pUBQ3gus, que contém o gene gus sob o controle do promotor do gene $U B Q 3$ de A. thaliana (Callis et al., 1995); e o plasmídeo pZSL11, que contém o gene gus sob o controle de um promotor constitutivo do gene que codifica a enzima S-adenosyl-L-methionine synthetase (SAMS), a qual é encontrada em plantas ( http://12.espacenet.com/dips/ viewer?PN=WO0037662\&CY=ep\&LG=en\&DB=EPD ).

Para a videira 'Cabernet Sauvignon', foram preparadas quatro placas para cada tipo de tecido utilizado (folhas, caules e calos). Da mesma forma, para 'Paulsen-1103', foram preparadas quatro placas para cada tipo de tecido (folhas, caules, raízes e calos). Para o mamoeiro, foram preparadas quatro placas para cada tipo de tecido (embrião somático, folhas, fruto superfície, fruto cortado, caule superfície, caule cortado, raiz superfície e raiz cortada).

O método utilizado para a transformação dos tecidos foi de biobalística (Sanford, 1990). O DNA utilizado foi preparado segundo Aragão et al. (1996) com algumas adaptações. Cada placa foi bombardeada duas vezes, utilizando-se de $1 \mu \mathrm{g}$ de DNA precipitado em $600 \mu \mathrm{g}$ de micropartículas (M10) de tungstênio por bombardeamento. O bombardeamento foi realizado em aparelho de biobalística com o gás hélio sob pressão de 1200 psi. Após este, os explantes foram mantidos em sala de crescimento $\left(25^{\circ} \pm 2^{\circ} \mathrm{C}\right.$ e fotoperíodo de 16 horas de luz) por 24 horas. Depois desse período, realizou-se o teste histoquímico, imergindo os explantes em solução X-Glu [0.5 $\mu \mathrm{g} / \mu 1$ 5-Bromo-4-Chloro-3-Indolyl bD-Glucuronide, dissolvido em 10 mM EDTA, sal dissódico + $100 \mathrm{mM}$ $\mathrm{NaH}_{2} \mathrm{PO}_{4} \cdot \mathrm{H}_{2} \mathrm{O}+0,5 \mathrm{mM} \mathrm{K} 4 \mathrm{Fe}(\mathrm{CN})_{6} \cdot 3 \mathrm{H}_{2} \mathrm{O}+0,1 \%$ Triton X-100]. Nessas condições, os explantes foram incubados no escuro, a $37^{\circ} \mathrm{C}$, por 16 horas. Depois desse período, analisou-se a presença ou ausência de pontos de coloração azul nos diferentes tecidos.

A análise da expressão transiente considerou como resultado positivo todo e qualquer tecido que apresentou uma ou mais células com coloração azul, após o teste histoquímico em X-Glu. Pontos azuis foram observados em embriões e folhas de mamoeiro (Figura 1) para todas as construções gênicas utilizadas (Tabela 1). Expressão do gene gus, sob a regulação do promotor CaMV $35 \mathrm{~S}$ e do terminador nos, já foi relatada por Tennant (1996) em folhas obtidas de plântulas de mamoeiro transgênico oriundas de sementes. A expressão transiente do gene gus na superfície do fruto do mamoeiro foi observada para todas as construções utilizadas, com exceção da pZSL11 (Tabela 1). No entanto, não foi possível observar expressão deste gene na polpa do fruto, independentemente da construção utilizada. Quando a expressão na superfície do caule foi avaliada, pontos azuis foram observados com a maioria das construções testadas, com exceção da construção pAG1. Da mesma forma que na polpa do fruto, nenhuma expressão transiente foi observada no tecido interno do caule. Nenhum dos promotores testados promoveu o aparecimento de sinais de expressão transiente em tecidos de raiz de mamoeiro (Tabela 1). A inexistência de resultado positivo de expressão transiente em tecidos internos de mamoeiro pode ser decorrente de inibição da b-glucuronidase por proteases liberadas quando os tecidos foram cortados.

Em relação aos diferentes tecidos testados para o mamoeiro, observou-se que não houve diferença entre os plasmídeos pUBQ3gus e pBI426, que possibilitaram a expressão do gene gus em embriões somáticos, folhas e superfícies de frutos e caules. Estes resultados sugerem que o promotor do gene $U B Q 3$ representa uma real alternativa ao uso do promotor de CaMV 35S-35S em mamoeiro. Todos os promotores promoveram a expressão em embriões somáticos. Tecidos embrionários são normalmente empregados para a seleção in vitro de plantas transgênicas de mamoeiro (Cai et al., 1999; Souza Jr. 1999). Estes resultados sugerem que qualquer um dos promotores testados poderia ser utilizado para regular a expressão de genes marcadores de seleção positiva de mamoeiros transgênicos.

Somente com a construção pZSL11, não foi possível observar a expressão transiente do gene gus na casca do fruto. Devido a limitações metodológicas, que não permitiram a obtenção de resultados conclusi- vos de expressão transiente na polpa do fruto, não foi possível saber se a construção pZSL11 tem ou não a mesma especificidade de expressão apresentada na superfície deste. A polpa do mamão é consumida principalmente in natura, sem processamento. Um promotor com expressão tecido-específica, que não se expressa na polpa do fruto teria um considerável potencial de uso nesta fruteira e em outras fruteiras, principalmente se o produto do transgene utilizado apresentasse limitações quanto à segurança alimentar; isto é, toxidez ou alergenicidade. Estudos complementares fazem-se necessários, principalmente no que se refere à expressão estável do gene gus nos diversos tecidos do fruto, para que se tenha uma análise mais completa da expressão destes promotores em tecidos do fruto.

TABELA 1 - Expressão transiente do gene gus em diferentes tecidos de mamoeiro (Carica papaya) e videira (Vitis sp.).

\begin{tabular}{llllll}
\hline Cultura & Tecido & \multicolumn{4}{c}{ Construção } \\
\cline { 3 - 6 } & & pBI426 $^{\mathbf{1}}$ & pUB3gus $^{\mathbf{2}}$ & pAG1 $^{\mathbf{3}}$ & pZSL11 $^{\mathbf{4}}$ \\
\hline Mamoeiro & Embrião & Positiva* $^{*}$ & Positiva & Positiva & Positiva \\
& somático & & & & \\
& Folha & Positiva & Positiva & Positiva & Positiva \\
& Fruto C & Positiva & Positiva & Positiva & Negativa \\
& Fruto $\mathrm{P}^{6}$ & Negativa & Negativa & Negativa & Negativa \\
& Caule E & Positiva & Positiva & Negativa & Positiva \\
& Caule I ${ }^{8}$ & Negativa & Negativa & Negativa & Negativa \\
& Raiz E & Negativa & Negativa & Negativa & Negativa \\
Videira - & Raiz I & Negativa & Negativa & Negativa & Negativa \\
Porta-enxerto & & & & & \\
& & & & & \\
& Caule & Positiva & Positiva & Negativa & Positiva \\
& Raiz & Positiva & Negativa & Negativa & Positiva \\
& Calo & Negativa & Negativa & Negativa & Negativa \\
Videira - Copa & Folha & Negativa & Negativa & Negativa & Negativa \\
& & & & & \\
& Caule & Positiva & Negativa & Negativa & Positiva \\
& Calo & Negativa & Negativa & Negativa & Negativa \\
& Folha & Negativa & Negativa & Negativa & Negativa \\
\hline
\end{tabular}

* considerou-se como resultado positivo todo e qualquer tecido que apresentou uma ou mais células com coloração azul, após o teste histoquímico em X-Glu. Gene gus sob o controle do promotor: 1 - CaMV 35S-35S (Datla et al., 1991); 2 - do gene UBQ3 (Silveira et al., 2000); 3 - do gene act2 (Aragão et al., 2000); e 4 SAMS (http://12.espacenet.com/dips viewer?PN=WO0037662\&CY=ep\&LG $=$ en $\& D B=E P D$ ). Tecido: 5 - Casca do fruto; 6 - Polpa do fruto; 7 - Tecido externo; e 8 - Tecido interno.

Para 'Paulsen 1103', resultados positivos de expressão transiente do gene gus foram obtidos em caules (Figura 1) e raízes, mas não nos demais tecidos testados. Somente a construção pAG1 não apresentou expressão deste gene em nenhum tecido de videira testado. Nas raízes, pontos azuis foram observados quando estes tecidos foram bombardeados com as construções pBI426 e pZSL11, mas não com as demais (Tabela 1). Martinelli \& Mandolino (1994) obtiveram resultados positivos de expressão do gene gus, sob a regulação do promotor CaMV 35S e terminador nos em embriões somáticos secundários de Vitis rupestris S. O portaenxerto 'Paulsen 1103' é híbrido de V. Berlandieri e V. rupestris. Para Vitis sp., o promotor mais utilizado em transformação genética é o CaMV 35S35S (Kikkert et al. 1997; Martinelli et al., 1994). As construções pBI426 e pZSL11 apresentaram a mesma especificidade para expressão transiente neste porta-enxerto, o que sugere que este promotor pode representar uma alternativa ao CaMV 35S-35S em transformação de videira.

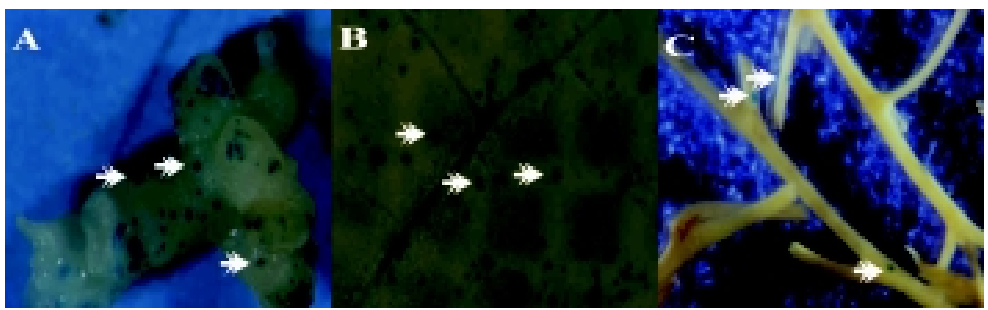

FIGURA 1 - Expressão transiente do gene $g u s$ em diferentes tecidos de fruteiras. A e B - Respectivamente, embriões somáticos e folha de mamoeiro (Carica papaya cv. Sunrise) transformados com vetor pUB3 gus, e C - Caules de videira (Porta-enxerto Paulsen 1103) transformado com pZSL11. Setas indicam resultados positivos. 
Quando se trata de porta-enxertos, é importante que a expressão de um gene inserido ocorra principalmente nos tecidos de raiz e de caule. Os resultados obtidos revelam que o promotor do gene $U B Q 3$ promoveu a expressão do gene gus apenas em caules de videira (Tabela 1). Estudos complementares de expressão estável, nos diferentes tecidos de videira, fazem-se necessários. Se estes estudos revelarem a mesma especificidade de expressão para o promotor do gene $U B Q 3$, este não poderá ser utilizado quando objetivando características dependentes de expressão na raiz, como, por exemplo, resistência a "margarodes" (Eurizoccocus brasiliensis) ou a nematóides.

Para "Cabernet Sauvignon", resultados positivos de expressão transiente foram observados apenas nos caules. Estes tecidos apresentaram pontos azuis, após o teste histoquímico em X-Glu, quando bombardeados com as construções pBI426 e pZSL11 (Tabela 1). Kikkert et al. (1997) reportam expressão transiente do gene gus sob o controle do promotor CaMV 35S-35S, utilizando a construção pBI426 para o bombardeamento de células embriogênicas das variedades 'Merlot' e 'Chancellor'. No caso de variedades-copa, é importante que os promotores sejam eficientes para promover a expressão em tecidos da copa, como folhas, caule e frutos. Os resultados obtidos (Tabela 1) revelam que o promotor do gene $U B Q 3$ não foi eficiente para promover a expressão em nenhum dos tecidos testados, sendo, para tanto, menos eficiente em relação aos promotores que regulam o gene gus em pBI426 e pZSL11.

Um dos principais tecidos atacados por doenças fúngicas na videira são as folhas. Nenhum dos promotores utilizados no presente estudo permitiu a expressão transiente do gene gus neste tecido. Expressão estável deste gene foi observada em folhas, caules, raízes, anteras e ovários quando sob a regulação do promotor CaMV 35S-35S (Kikkert et al., 1997). Estes autores relatam expressão estável do gene gus nos tecidos da variedade-copa 'Chancellor'. A não-expressão deste gene de forma transiente em folhas de 'Cabernet Sauvignon' e 'Paulsen 1103' (Tabela 1) pode ser decorrente de limitações metodológicas ou resultado de uma especificidade de expressão em nível de variedade. Estudos complementares precisam ser realizados para melhor esclarecer este ponto.

Com base nos resultados obtidos, nas condições experimentais do presente trabalho, pôde-se concluir que: a) o promotor do gene $U B Q 3$ é uma alternativa real ao CaMV 35S-35S para futuros trabalhos de transformação genética de mamoeiro; b) o promotor SAMS mostrou-se como a melhor alternativa, dentre as testadas, ao CaMV 35S-35S, para futuros trabalhos de transformação genética de videira.

\section{REFERÊNCIASBIBLIOGRÁFICAS}

ARAGÃO, F. J. L.; BARROS, L. M. G.; BRASILEIRO, A. C. M; RIBEIRO, S. G.; SMITH, F. D.; SANFORD, J. C.; FARIA, J. C.; RECH, E. L. Inheritance of foreign genes in transgenic bean (Phaseolus vulgaris L.) co-transformed via particle bombardment. Theoretical and Applied Genetics, Berlin, v.93, p.142-150, 1996.

ARAGÃO, F. J. L.; SAROKIN, L.; VIANNA, G. R.; RECH, E. L. Selection of transgenic meristematic cells utilizing a herbicidal molecule results in the recovery of fertile transgenic soybean (Glycine max L. Merril) plants at a high frequency. Theoretical and Applied Genetics, Berlin, v.101, p.1-6, 2000.

BENFEY, P. N.; CHUA, N. The cauliflower mosaic virus 35S promoter: combinatorial regulation of transcription in plants. Science, Washington, v.250, p.959-966, 1990.

BEVAN, M.; BRANES, W. M.; CHILTON, M-D. Structure and transcription of the nopaline synthase gene region of T-DNA. Nucleic Acids Research, Oxford, v.11, p.369-385, 1983.

CAI, W., GONSALVES, C., TENNANT, P., FERMIN, G., SOUZA JR., M.
T., SARINDU, N., JAN, F. J., ZHU, H. Y.; GONSALVES, D. A protocol for efficient transformation and regeneration of Carica papaya L. In Vitro Cellular \& Development Biology - Plant, Largo, v.351, 61-69, 1999.

CALLIS, J.; CARPENTER, T.; SUN, C.; VIERSTRA, R. D. Structure and evolution of genes encoding polyubiquitin and ubiquitin-like proteins in Arabidopsis thaliana ecotype columbia. Genetics, Maryland, v.139, p.921-939, 1995.

CAMARGO, U. A.; AMARAL, A. L.; OLIVEIRA, P. R. D. Uvas sem sementes. Biotecnologia, Brasília, v.10; p.108-112, 1999.

DATLA, R. S.; HAMMERLINDL, J. K.; PELCHER, L. E.; CROSBY, W.L.; SELVARAJ, G. A bifuntional fusion between beta-glucuronidase and neomycin phosphotransferase: a broad spectrum marker emzyme for plants. Gene, Madison, v.101, p.239-246, 1991.

FITCH, M.; MANSHARDT, R.; GONSALVES, D.; SLIGHTOM, J.; SANFORD, J. Virus resistant papaya plants derided from tissues bombarded with the coat protein gene of papaya ringspot virus. Bio/ Technology, New York v.10, p.1466-1472, 1992.

GILISSEN, L. J. W.; METZ, P. L. J.; STIEKEMA, W. J.; NAP, J. Biosafety of E. coli b-glucuronidase (GUS) in plants. Transgenic Research, London, v.7, p.157-163, 1998.

GONSALVES, D. Control of papaya ringspot virus in papaya: A case study. Annual Review Phytopathology, Wallingford, v.36, p.415-437, 1998.

ISHERWOOD, M. O. J. Papaya ringspot virus in Puna: chronology of events and eradication program up date. In: Annual Hawaii Papaya Ind. Assoc. Conf., 28., 1992, Honolulu, Anais... p.7-9.

JEFFERSON, R. A.; BURGESS, S. M.; HIRSH, D. b-glucuronidase from Escherichia coli as a gene fusion marker. Proceedings of the National Academic of Science, Washington, v.83, p.8447-8451, 1986.

KIKKERT, J.; ALI, G. S.; STRIEM, M. J.; MARTENS, M.; WALLACE, P.G.; MOLINO, L.; REISCH, B. I. Genetic engineering of grapevine (Vitis sp.) for enhancement of disease resistance. Acta Horticulturae, Wagenigeu, n.447, p.273-279, 1997.

MARTINELLI, L.; MANDOLINO, G. Genetic transformation and regeneration of transgenic plant in grapevine (Vitis rupestris $\mathrm{S}$.). Theoretical and Applied Genetics, Berlin, v.88, p.621-628, 1994.

MURASHIGE, T.; Skoog, F. A revised medium for rapid growth and bioassays with tobacco tissues cultures. Physiology of Plants, Rockville, v.15, p.473-497, 1962.

REZENDE, J. A.; COSTA, A. S. Doenças de vírus e micoplasma de mamoeiro. Summa Phytopathologica, Jaboticabal, v.19, p.73-79, 1993.

SANFORD, J. C. Biolistic plant transformation. Physiology of Plants, Rockville, v.79, p.206-209, 1990.

SOUZA JR., M. T. Analysis of the resistance in genetically engineered papaya against papaya ringspot potyvirus, partial characterization of the PRSV.Brazil.Bahia isolate, and development of transgenic papaya for Brazil. 1999. 277f. Dissertação (Ph.D.)-Department of Plant Pathology, Cornell University, Ithaca, NY, 1999.

TENNANT, P. F. Evaluation of the resistance of coat protein transgenic papaya against papaya ringspot virus isolates and development of transgenic papaya for Jamaica. 1996. 317f. Dissertação (Ph.D.) Department of Plant Pathology, Cornell University, Ithaca, NY, 1996.

YEH, S. D.; GONSALVES, D. Practices and perspective of control of papaya ringspot virus by cross protection. In: HARRIS, K. F. (Ed.) Advances in diseases vector research. New York: Springer-Verlag, 1994. v. 10, p.237-257.

YONG-QIANG, A.; McDOWELL, J.M.; HUANG, S.; McKINNEY, E. C.; CHAMBLISS, S.; MEAGHER, R.B. Strong constitutive expression of the Arabidopsis ACT2/ACT8 actin subclass in vegetative tissues. Plant Journal, Oxford, v.10, p.107-121, 1996. 